\title{
Influência das propriedades de forma da fração graúda do agregado no controle da deformação permanente de misturas asfálticas densas
}

\author{
Influence of the shape properties of the coarse aggregates in the control \\ of the permanent deformation of dense asphalt mixtures
}

\author{
Rodrigo Pires Leandro ${ }^{1}$, Kamilla Vasconcelos Savasini ${ }^{2}$, Liedi Legi Bariani Bernucci ${ }^{3}$, \\ Verônica Teixeira Franco Castelo Branco ${ }^{4}$ \\ 1Universidade Federal de Uberlândia, Minas Gerais - Brasil, rodrigo.leandro@ufu.br \\ 2Universidade de São Paulo, São Paulo - Brasil, kamilla.vasconcelos@usp.br \\ 3Universidade de São Paulo, São Paulo - Brasil, liedi@usp.br \\ ${ }^{4}$ Universidade Federal do Ceará, Ceará - Brasil, veronica@det.ufc.br
}

\section{Recebido:}

9 de maio de 2020

Aceito para publicação:

22 de setembro de 2020

Publicado:

18 de agosto de 2021

Editor de área:

Jorge Barbosa Soares

\section{Palavras-chave:}

Deformação permanente.

Método Bailey.

Agregados graúdos.

Misturas asfálticas.

Propriedades de forma.

Keywords:

Permanent deformation.

Bailey Method.

Coarse aggregates.

Hot mix asphalt.

Shape properties.

DOI:10.14295/transportes.v29i2.2395

\section{RESUMO}

Em regiões de clima quente, sujeitas a tráfego pesado, os efeitos da deformação permanente se tornam um dos mais importantes problemas dos concretos asfálticos. O travamento do esqueleto de agregados, para um certo teor de ligante, contribui com o aumento da estabilidade da mistura asfáltica e da resistência aos afundamentos por deformação permanente. 0 método Bailey, avaliado nesse trabalho de maneira complementar, foi concebido para garantir adequada distribuição granulométrica para melhorar o comportamento dos concretos asfálticos quanto ao afundamento em trilha de roda. O propósito desse estudo foi avaliar a influência do tipo de agregado da fração graúda e das suas propriedades de forma no controle da deformação permanente de misturas asfálticas densas. Para a formulação das misturas asfálticas foram utilizados um ligante asfáltico convencional (CAP 50/70) e agregados de duas origens: (i) granítico britado, e (ii) seixo rolado britado e natural (sem britagem). A partir dos resultados dos ensaios de afundamento em trilha de roda, no simulador de tráfego do tipo LCPC, constatou-se que a fração graúda e, principalmente, as propriedades de forma dos agregados influenciaram o comportamento quanto à deformação permanente das misturas asfálticas densas avaliadas nesse estudo.

\section{ABSTRACT}

Rutting is a common type of distress in asphalt pavements. This is more evident for warm regions and heavy traffic. The locking of the aggregate skeleton associated with the binder content contributes to increasing the stability of the asphalt mixture. The objective of the Bailey method, evaluated secondarily in this study, is to ensure aggregate interlock and good aggregate packing, giving resistance to permanent deformation. The purpose of this study was to evaluate the influence of the type and the shape properties of the aggregates (coarse fraction) in the control of the permanent deformation of dense asphalt mixtures. The asphalt binder used in this study was a neat binder classified by penetration (50/70 PEN). The aggregates used are: (i) one from granitic source and (ii) one gravel (crushed and not crushed). It was found that LCPC wheel tracking test results pointed out that the asphalt mix resistance to rutting depends on the aggregate source, especially its shape. 


\section{INTRODUCÃO}

As tensões provenientes do tráfego geram três tipos de solicitação nos revestimentos asfálticos de pavimentos flexíveis: cisalhamento, tração e compressão. Quando os revestimentos asfálticos trabalham à flexão, as tensões de tração repetidas provocam o trincamento por fadiga. As solicitações de cisalhamento e de compressão são responsáveis pelas deformações permanentes que, acumuladas ao longo do tempo, provocam o Afundamento nas Trilhas de Roda (ATR). Nos concretos asfálticos, apesar do ligante estar presente em menor quantidade, a sua característica viscoelástica manifesta-se na resposta mecânica da mistura. Então, o desempenho da mistura é dependente das características do carregamento associadas à temperatura de operação em pista. Em regiões de clima quente, os agregados desempenham papel ainda mais importante na resistência à deformação permanente. Uma distribuição granulométrica bem graduada, gerando adequado intertravamento, resulta em maior resistência a esse tipo de deformação (Huber et al., 1998; Moura, 2010). Misturas descontínuas também podem apresentar elevada resistência à deformação permanente devido ao contato entre os grãos de maior dimensão, como é o caso das misturas do tipo Stone Matrix Asphalt (SMA) (West e Moore, 2006).

0 método Bailey de composição granulométrica tem como proposta selecionar agregados de maneira a se obter maior intertravamento da fração graúda, o que contribui para o melhor desempenho das misturas asfálticas quanto aos efeitos da deformação permanente (Vavrik et al., 2002a). Entretanto, além da distribuição granulométrica, a morfologia dos agregados é considerada importante na promoção da estabilidade dos concretos asfálticos (Pan et al., 2006). Os agregados mais cúbicos e de textura superficial rugosa, juntamente com a maior quantidade de frações graúdas, auxiliam na redução do potencial de deformação permanente. Nesse sentido, a angularidade do agregado graúdo é apontada como um parâmetro de forma que exerce efeito relevante no desempenho quanto à deformação permanente de misturas asfálticas, principalmente quando ligantes menos consistentes são utilizados, ou em climas quentes com tráfego lento e pesado (Stakston et al., 2003; Huang et al., 2009).

Para este trabalho dois questionamentos foram elaborados: (i) qual a contribuição da fração graúda de agregados no comportamento quanto à deformação permanente da mistura asfáltica? (ii) esta contribuição na resistência à deformação permanente da mistura é devida, em maior parte, à distribuição granulométrica, ou às propriedades de forma dos agregados? Essas indagações representam preocupações que devem ser consideradas ainda no momento do projeto da mistura asfáltica e motivaram o objetivo principal desse trabalho que é a avaliação da influência da forma da fração graúda do agregado quanto à resistência a deformação permanente de misturas asfálticas densas.

\section{DEFORMAÇÃO PERMANENTE DE MISTURAS ASFÁLTICAS DENSAS}

O ATR, por acúmulo de deformação permanente, ocorre devido a dois mecanismos: uma combinação da densificação (redução do volume de vazios) e da deformação cisalhante (Yoder e Witzak, 1975). 0 mecanismo de ocorrência da deformação permanente por densificação pode ser entendido como a deformação vertical por consolidação ou a compactação pósconstrução. Nesse caso, ocorre diminuição do volume de vazios da camada (Carvalho, 1997). Nos concretos asfálticos, o volume de vazios, após a compactação durante a construção, deve ser de cerca de 6 a 8\% e espera-se que este seja reduzido pela ação do tráfego para valores entre 4 e 5\% após dois a três anos de operação (Roberts, 1996; Watson et al., 2005). 0 mecanismo de ocorrência da deformação permanente por cisalhamento ocorre quando o material da camada 
não pode mais ser densificado pelo tráfego e, não suportando as tensões do mesmo, desloca-se para fora da zona solicitada (Roberts, 1996).

Diferentes tipos de ensaios podem ser utilizados para a avaliação das misturas asfálticas quanto à resistência à deformação permanente. 0 ensaio uniaxial de carga repetida tem o objetivo de determinar o número de ciclos acumulado que leva o corpo de prova à taxa de deformação plástica mínima. A partir desse citado ciclo a amostra entra na zona terciária de deformação, passando a sofrer cisalhamento a volume constante (Witczak et al., 2002). Outro ensaio de carga repetida utilizado para avaliar a deformação permanente é o Triaxial Stress Sweep (TSS,) que é um ensaio de compressão vertical cíclica e confinamento constante. A utilização do ensaio de TSS associado ao Shift Model e ao programa FlexPAVE possibilita a previsão do desempenho de pavimentos asfálticos quanto a esse tipo de falha (Eslaminia et al., 2012; Choi e Kim, 2014; Bastos, 2016; Wang et al., 2016). Esse ensaio considera os efeitos da temperatura, do tempo de carregamento e da tensão desvio sobre a deformação permanente. Contudo, o procedimento demanda um conjunto de quatro ensaios e duas réplicas por ensaio, exigindo dois dias para a realização completa do teste. Assim, desenvolveu-se, como alternativa simplificada, o ensaio Stress Sweep Rutting (SSR) que demanda menor quantidade de ensaios e menor tempo de realização (Kim e Kim, 2017).

No método francês de dosagem de misturas asfálticas, a avaliação da resistência à deformação permanente é realizada em placas moldadas em laboratório por rolagem de um pneumático e que são testadas no simulador de tráfego de laboratório do tipo LCPC. As placas compactadas são submetidas a ciclos de carga por um pneumático em movimentos longitudinais de ida e volta sempre em contato com a superfície da placa de mistura asfáltica compactada (Bernucci et al., 2010). Porcentagens de afundamento superiores a $10 \%$ inviabilizam o uso da mistura asfáltica densa para qualquer condição de tráfego. Deformações de até $5 \%$ garantem que o revestimento asfáltico irá deformar-se dentro do limite aceitável em campo, gerando limitados afundamentos (Moura, 2010). Vale salientar, porém, que existem formulações do método francês que possuem característica densa e que, a depender da classe, podem chegar a 15\% de ATR, estando de acordo com a normativa francesa (LCPC, 1994; MANUEL LPC, 2007).

Segundo Harvey et al. (2009), deformações cisalhantes que levam ao afundamento são limitadas à parte superior da camada dos revestimentos asfálticos. Assim, testes de laboratório que avaliem, principalmente, deformações de cisalhamento serão mais efetivos para a verificação da propensão à deformação permanente. A partir dessa limitação, Harvey et al. (2009) recomendam que as amostras destinadas ao estudo dos efeitos da deformação permanente em misturas asfálticas sejam preparadas utilizando compactação por rolagem para garantir que o esqueleto de agregado seja representativo daquele obtido em pista. Nesse sentido, a compactação por rolagem é a que melhor simula a compactação de campo e que produz corpos de prova com volumetria, distribuição dos constituintes e comportamento mecânico, semelhantes aos extraídos de pista (Sousa et al., 1991; Khan et al., 1998; Vasconcelos et al., 2005; Hunter et al., 2009; Dubois et al., 2011; Leandro et al., 2017).

\section{O MÉTODO BAILEY DE COMPOSIÇÃO GRANULOMÉTRICA}

0 método Bailey está relacionado às características de compactação de cada uma das frações dos agregados, dadas pelo VMA (Voids in the Mineral Aggregate ou vazios no agregado mineral) e pelo Va (Air Voids ou volume de vazios com ar) (Cunha, 2004). 0 objetivo do método é seleci- 
onar uma matriz pétrea de forma a gerar maior intertravamento dos agregados graúdos garantindo adequado desempenho da mistura quanto à deformação permanente (Vavrik et al., $2002^{\mathrm{a}}$ ), além de propor um VMA adequado.

No método Bailey, a mistura de agregados é dividida em três porções distintas, onde cada uma é avaliada, individualmente, em função das peneiras de controle. Essas peneiras são função do Tamanho Máximo Nominal (TMN) do agregado. A peneira que define a divisão entre agregado graúdo e miúdo é a Peneira de Controle Primário (PCP) que pode ser considerada como sendo a peneira com a abertura de malha mais próxima do resultado do TMN $\times 0,22$. 0 agregado miúdo, por sua vez, é dividido e analisado em duas porções. A divisão do agregado miúdo é feita através da multiplicação da PCP pelo fator 0,22, que fornece a Peneira de Controle Secundário (PCS). Essa peneira representa a divisão entre as frações graúda e fina do agregado miúdo. A fração fina do agregado miúdo é avaliada pela Peneira de Controle Terciário (PCT), que é determinada multiplicando-se a PCS pelo fator de 0,22 .

0 fator 0,22 é denominado de fator de compactação e é resultante de análises, em duas dimensões, da compactação de agregados de diferentes formas. As análises foram baseadas em quatro combinações de características geométricas dos agregados. As análises de combinação de faces arredondadas e planas resultaram nos seguintes fatores: 0,15 para partículas com todas as faces arredondadas; 0,20 para duas faces arredondadas e uma plana; 0,24 para uma face arredondada e duas faces planas e 0,29 para todas as faces planas. Embora o fator de compactação varie de acordo com as características físicas dos agregados, por simplificação, o fator de 0,22 foi adotado para as diversas formas de partículas de uma mistura asfáltica (Vavrik et al., 2002a). A partir dessa simplificação, vislumbra-se que agregados com propriedades de forma distintas das atribuídas como padrão por Vavrik et al. (2002 $\left.{ }^{\mathrm{a}}\right)$ podem gerar esqueletos pétreos de menor resistência aos efeitos da deformação permanente.

Para a avaliação da compactação de cada uma das três proporções da granulometria selecionada, o método define três parâmetros: (1) proporção de agregados graúdos (AG); (2) proporção de agregados graúdos do agregado miúdo (GAF) e; (3) proporção fina do agregado miúdo (FAF). 0 índice AG avalia a compactação da porção graúda e é considerado, por Vavrik et al. $\left(2002^{\mathrm{a}}\right)$, como o fator mais importante para a seleção da mistura, estando relacionado com o potencial de segregação e compactabilidade da mesma. 0 GAF indica a quantidade da porção fina do agregado miúdo que deve preencher os vazios de modo adequado, garantindo espaço vazio necessário para a inserção do ligante asfáltico, ou seja, o GAF tem impacto nos valores de VMA. O FAF indica como a porção fina do agregado miúdo é compactada. Diversos pesquisadores têm mostrado benefícios da utilização do método Bailey quanto ao comportamento à deformação permanente de misturas asfálticas (Botasso et al., 2014; Manjunath e Poornachandra, 2014; Bastos, 2016; Mohamed et al., 2016).

Existe diferença quanto à definição da Peneira Média (PM) para distribuições granulométricas de TMN de 12,5mm entre o método Bailey apresentado no trabalho de Vavrik et al. (2002a) e o de Vavrik et al. (2002 b). De acordo com o primeiro trabalho, a peneira de abertura de malha de $4,75 \mathrm{~mm}$ poderia ser definida como PM. Contudo, as atualizações propostas em $2002^{\mathrm{b}}$ recomendam a estimativa por interpolação do percentual passante na peneira de abertura de malha 6,25mm para o cálculo dos parâmetros do método Bailey. A justificativa dessa alteração é a obtenção de uma situação mais representativa da graduação e potencial intertravamento (Vavrik et al., 2002b). 


\section{MATERIAIS E MÉTODOS}

As atividades necessárias para se atingir o objetivo geral proposto neste trabalho foram estruturadas em etapas que são descritas nos itens a seguir. Na Figura 1 é mostrado o fluxograma do método experimental elaborado com base nessas etapas.

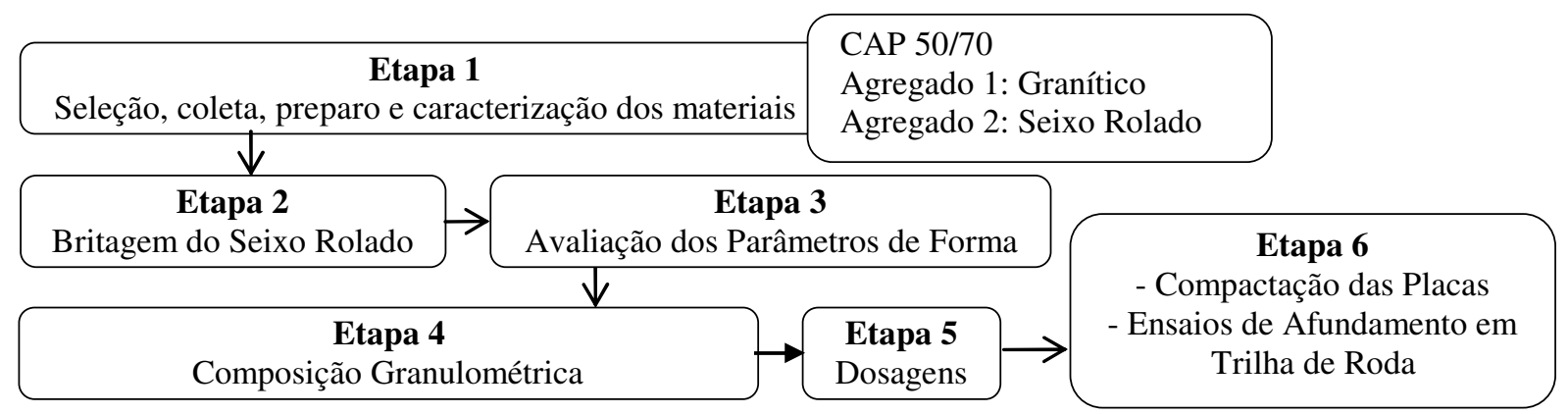

Figura 1. Fluxograma do método experimental em laboratório

\subsection{Seleção, Coleta, Preparo e Caracterização dos Materiais}

Os materiais foram selecionados de modo a viabilizar as análises necessárias para o atendimento do objetivo estabelecido. Selecionou-se uma mistura asfáltica de referência fabricada com materiais de propriedades conhecidas. Optou-se pela utilização de um agregado granítico que foi objeto de estudo em pistas experimentais realizado por Moura (2010). Tendo em vista que o propósito deste trabalho foi a avalição dos efeitos do tipo de agregado (fração graúda > $2 \mathrm{~mm}$ ) e de suas propriedades de forma, coletou-se também agregado natural de rio denominado por "seixo rolado". Para evidenciar os efeitos dos agregados e do esqueleto pétreo, utilizouse um ligante de menor consistência (CAP 50/70 de penetração de $59 \times 10^{-1} \mathrm{~mm}$ ). Na Tabela 1 é mostrada a caracterização dos agregados utilizados no estudo.

Tabela 1 - Caracterização dos agregados

\begin{tabular}{lllllll}
\hline \multirow{2}{*}{ Parâmetro } & \multirow{2}{*}{ Unidade } & \multicolumn{2}{l}{ Material } & & \\
\cline { 3 - 7 } & & Brita & Pedrisco & Pó de Pedra & Cal Hidratada & Seixo \\
\hline \% Partículas alongadas e achatadas $(>5: 1)$ & $\%$ & 4 & 6 & - & - & 0 \\
\% Partículas alongadas e achatadas (> 3:1) & $\%$ & 34 & 40 & - & - & 2 \\
Abrasão Los Angeles & $\%$ & 15,6 & 18,9 & - & - & 22,0 \\
Densidade real & - & 2,766 & 2,773 & 2,775 & 2,344 & 2,650 \\
Densidade aparente & - & 2,750 & 2,740 & 2,741 & - & 2,622 \\
Absorção & $\%$ & 0,20 & 0,40 & 0,40 & - & 0,41 \\
\hline
\end{tabular}

Nota-se da Tabela 1, que o percentual de partículas alongadas e achatadas de agregados graníticos na relação de 5:1 é pequena em relação ao limite de 10\% sugerido pelo Superpave. Contudo, chama atenção a quantidade de partículas alongadas e achatadas na razão de 3:1. Agregados com esta relação ou maior e com proporção superior a 30\% na mistura, afetam os parâmetros volumétricos, aumentando o volume de vazios e a suscetibilidade à degradação das partículas sob a ação do tráfego (Vavrik et al., 1999; Buchanan, 2000).

Para a avaliação do efeito do tipo de agregado da fração graúda, foram elaboradas duas misturas asfálticas com CAP 50/70, sendo uma constituída por agregados graníticos e a outra teve a fração maior que $2 \mathrm{~mm}$ (fração graúda) substituída por seixo. Num segundo cenário, de modo 
a se eliminar o efeito do tipo de agregado e analisar exclusivamente a influência dos parâmetros de forma, fez-se a britagem do seixo e realizou-se um novo conjunto de ensaios, mantendo-se a mesma distribuição granulométrica, a mesma origem do agregado (seixo) para uma varredura de teor de ligante $(4,5$ e 6\%). Os teores de projeto de cada uma das misturas estão dentro dessa faixa.

\subsection{Britagem do Seixo}

O seixo rolado foi submetido ao processo de britagem com o objetivo de alterar seus parâmetros de forma. A influência desses parâmetros no comportamento quanto à deformação permanente foi analisada por meio de ensaios de ATR. 0 procedimento de britagem foi definido após a execução de testes prévios em britadores do tipo mandíbula e de rolos. Depois de cada teste, foi feita a inspeção visual das partículas de seixo com o propósito de se avaliar as alterações no número de faces fraturadas. Assim, para partículas menores que 4,75mm utilizou-se o britador de rolos, fazendo-se duas passagens do material pelo equipamento. Para partículas maiores que 4,75mm, optou-se pelo britador de mandíbulas, também com duas passagens do material por esse equipamento. Para esse trabalho, denominou-se como "fração graúda" partículas maiores que $2 \mathrm{~mm}$. Na Figura 2 são apresentados, para ilustração, agregados retidos na peneira de $12,5 \mathrm{~mm}$ e utilizados no trabalho.

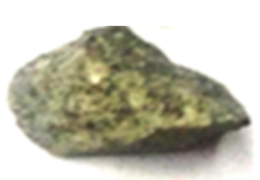

(a)

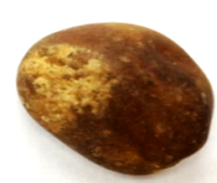

(b)

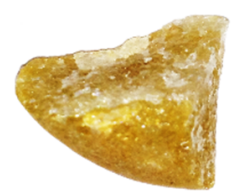

(c)

Figura 2. Aspecto da forma dos agregados utilizados (retidos na peneira de abertura de malha 12,5mm): (a) agregado granítico, (b) seixo e (c) seixo britado.

\subsection{Avaliação das Propriedades de Forma}

A avaliação das propriedades de forma dos agregados foi feita por meio do processamento digital de imagens no equipamento AIMS (Aggregate Imaging Measurement System). A avaliação concentrou-se nas frações maiores que $2 \mathrm{~mm}$, uma vez que a fração miúda das misturas asfálticas não foi alterada. A classificação dos parâmetros de forma foi realizada de acordo com Ibiapina et al. (2018).

\subsection{Composição Granulométrica das Misturas Asfálticas}

A distribuição granulométrica adotada não foi uma variável no estudo, sendo esta mantida constante para todos os cenários. A distribuição escolhida enquadra-se na característica de uma mistura 12,5mm do Superpave. Para atingir a distribuição granulométrica adotada (Figura 3), os agregados foram fracionados peneira a peneira.

Ao se considerar os trabalhos de Vavrik et al. (2002a) e Vavrik et al. (2002 $)$, tem-se dois cenários distintos quanto ao que se esperar do comportamento da fração graúda decorrente da distribuição granulométrica da Figura 3. Tomando-se como referência o trabalho de 2002a, a mistura atenderia aos parâmetros do método Bailey com proporção $A G$ de $0,53(0,5 \leq \mathrm{AG} \leq$ 
0,65). Entretanto, estimando-se o percentual passante para o diâmetro de 6,25mm por interpolação, conforme o recomendado no trabalho de $2002^{\text {b }}$, tem-se um parâmetro AG de 0,98 , caracterizando esta como uma mistura desbalanceada. Nessa última situação, as partículas que passam pela peneira PM tendem a controlar o esqueleto da fração graúda.

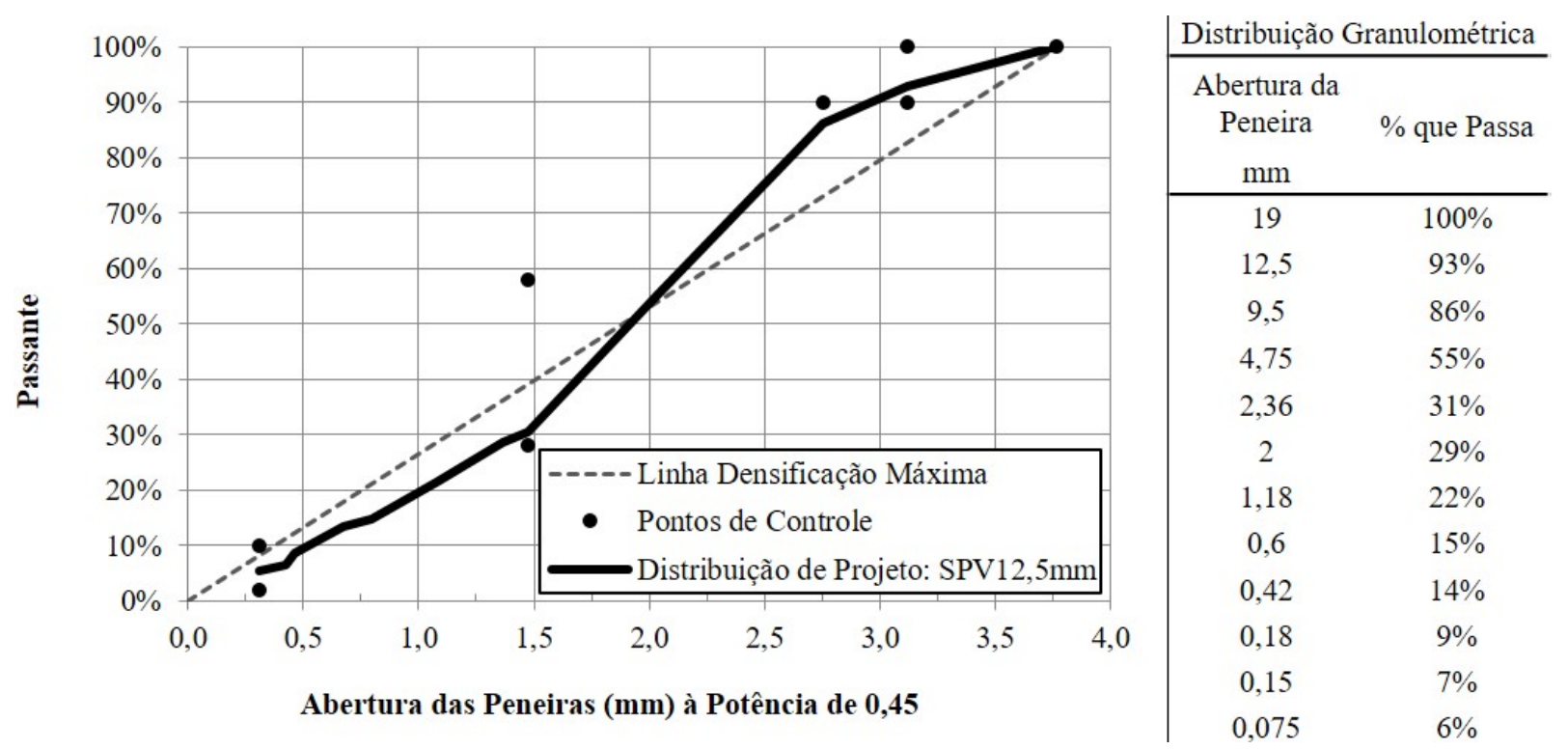

Figura 3. Distribuição granulométrica utilizada para a formulação das misturas asfálticas

\subsection{Dosagem das Misturas Asfálticas}

A quinta etapa do método experimental foi concentrada na determinação dos teores de ligante asfáltico de projeto utilizando a compactação Marshall (DNER ME 43/95) com aplicação de 75 golpes por face. A determinação da densidade aparente dos corpos de prova compactados foi feita considerando a ASTM D 2726 (2013) e a ASTM D 1188 (2007). A determinação da densidade máxima foi realizada através do método RICE (ASTM D 2041, 2011). Utilizou-se, como critério de avaliação dos parâmetros volumétricos, a especificação do Asphalt Institute (2001) e procurou-se atender ao critério de $4 \%$ de volume de vazios, respeitando-se, concomitantemente, os limites estabelecidos pelo Asphalt Institute para o VMA e o VFA (Voids Filled with Asphalt - vazios preenchidos por asfalto). Nessa etapa, também foram realizados ensaios de Dano por Umidade Induzida (DUI) (AASHTO T 283-89, 1989) nas misturas. Para todos os casos, os resultados de Resistência à Tração Retida (RTR) foram superiores a 90\%, indicando não haver problemas quanto ao DUI.

\subsection{Ensaios de Afundamento em Trilha de Roda (ATR)}

Nessa fase, os resultados dos ensaios de ATR de misturas elaboradas com o agregado granítico foram comparados com os resultados de misturas tendo como agregado o seixo (sem britagem) e, posteriormente, o seixo britado. A moldagem das placas foi realizada na mesa compactadora francesa por rolagem pneumática. 0 número e a posição das passadas, bem como as pressões aplicadas, são especificadas pela EN 12697-32:2003 (2007). As placas foram moldadas com $50 \mathrm{~mm}$ de altura, $150 \mathrm{~mm}$ de largura e $500 \mathrm{~mm}$ de comprimento. Após três dias da compactação, as placas foram submetidas ao ensaio de ATR no equipamento simulador francês com base na EN 12697-22:2003 (2007). 
Nessa etapa, foram ensaiados um par de placas fabricadas com agregado granítico, um segundo par de placas onde a parcela da distribuição granulométrica maior que $2 \mathrm{~mm}(71,2 \% \mathrm{em}$ peso) foi substituída por frações de seixo rolado e, por fim, mais um par de placas em que as frações maiores que $2 \mathrm{~mm}$ do agregado granítico foram substituídas por frações de seixo britado. Os ensaios de ATR foram feitos mantendo-se o mesmo tipo de ligante e fazendo-se uma varredura dos teores $(4,5$ e $6 \%)$.

\section{APRESENTAÇÃO E ANÁLISE DOS RESULTADOS}

Além do tipo de agregado e da estrutura pétrea, o teor de ligante é outro fator determinante no desempenho quanto à deformação permanente de um concreto asfáltico. Os teores de projeto determinados pela dosagem Marshall e os parâmetros volumétricos em função do tipo de agregado utilizado são apresentados na Tabela 2. Observa-se, a partir da Tabela 2, que a substituição da fração graúda do agregado granítico pela fração graúda de seixo e de seixo britado implicou em alterações consideráveis dos teores de ligante de projeto (de 4,7 a 5,9\%). A mistura com seixo não britado demandou menor quantidade de ligante $(4,7 \%)$, mas após o processo de britagem, o teor necessário de ligante aumentou em 1,2\%, sendo superior inclusive àquele determinado para a mistura composta apenas por agregado granítico. Essa maior demanda por ligante, após a britagem do seixo, é decorrente das alterações dos parâmetros de forma que impuseram maior dificuldade de compactação e maior área para recobrimento, apesar de mantidas a granulometria e as dimensões de controle dos agregados.

Tabela 2 - Teores de projeto e parâmetros volumétricos

\begin{tabular}{|c|c|c|c|c|c|}
\hline \multirow[b]{2}{*}{ Tipo de Ligante } & \multirow[b]{2}{*}{ Tipo de Agregado } & \multicolumn{4}{|l|}{ Parâmetro } \\
\hline & & $\begin{array}{l}\text { Teor de Ligante de Projeto } \\
\text { (\%) }\end{array}$ & $\begin{array}{l}V^{1} \\
(\%)\end{array}$ & $\begin{array}{l}\mathrm{VMA}^{2} \\
(\%)\end{array}$ & $\begin{array}{l}\mathrm{VFA}^{3} \\
(\%)\end{array}$ \\
\hline \multirow{3}{*}{ CAP 50/70 } & Seixo Não Britado (SNB) & 4,7 & 4,0 & 15,2 & 74,0 \\
\hline & Seixo Britado (SB) & 5,9 & 4,3 & 18,3 & 75,0 \\
\hline & Granítico & 5,5 & 4,2 & 17,0 & 74,0 \\
\hline
\end{tabular}

Na Figura 4 são apresentados os resultados de percentual de ATR no equipamento simulador francês para as três condições do estudo: agregado granítico, seixo não britado e seixo britado. Cada curva representa a média de duas placas testadas no simulador de tráfego. Os modelos de regressão, em termos de profundidade de afundamento para aplicações de 30.000 ciclos, são mostrados na Tabela 3 na forma da equação (1).

$$
Y=A\left(\frac{N}{1000}\right)^{b}
$$

em que $\quad Y: \quad$ é a profundidade de afundamento a $\mathrm{N}$ ciclos (30.000 ciclos);

A: $\quad$ é a profundidade de afundamento a 1.000 ciclos;

$b$ : $\quad$ é a inclinação da reta em escala logarítmica.

$\mathrm{O}$ efeito do tipo de agregado na resistência ao ATR, incluindo suas particularidades quanto à forma e à textura, fica evidente na Figura 4. Vê-se que, mesmo mantendo-se a mesma distribuição granulométrica, a substituição da parcela graúda do agregado granítico pelo seixo não britado e pelo seixo britado, resultou em deformações excessivas (maiores que $10 \%$ entre 400 e 3.000 ciclos). A mistura contendo agregado granítico foi considerada resistente à deformação permanente para uso em condições de tráfego pesado e muito pesado pelo método francês, 
uma vez que o percentual de afundamento ficou abaixo do limite de $5 \%$. Esse comportamento pode ser creditado ao tipo de agregado utilizado, incluindo suas propriedades de forma e textura, uma vez que a substituição da fração graúda do agregado de referência por seixo resultou em afundamento de $10 \%$ já para os primeiros 400 ciclos de aplicação de carga.

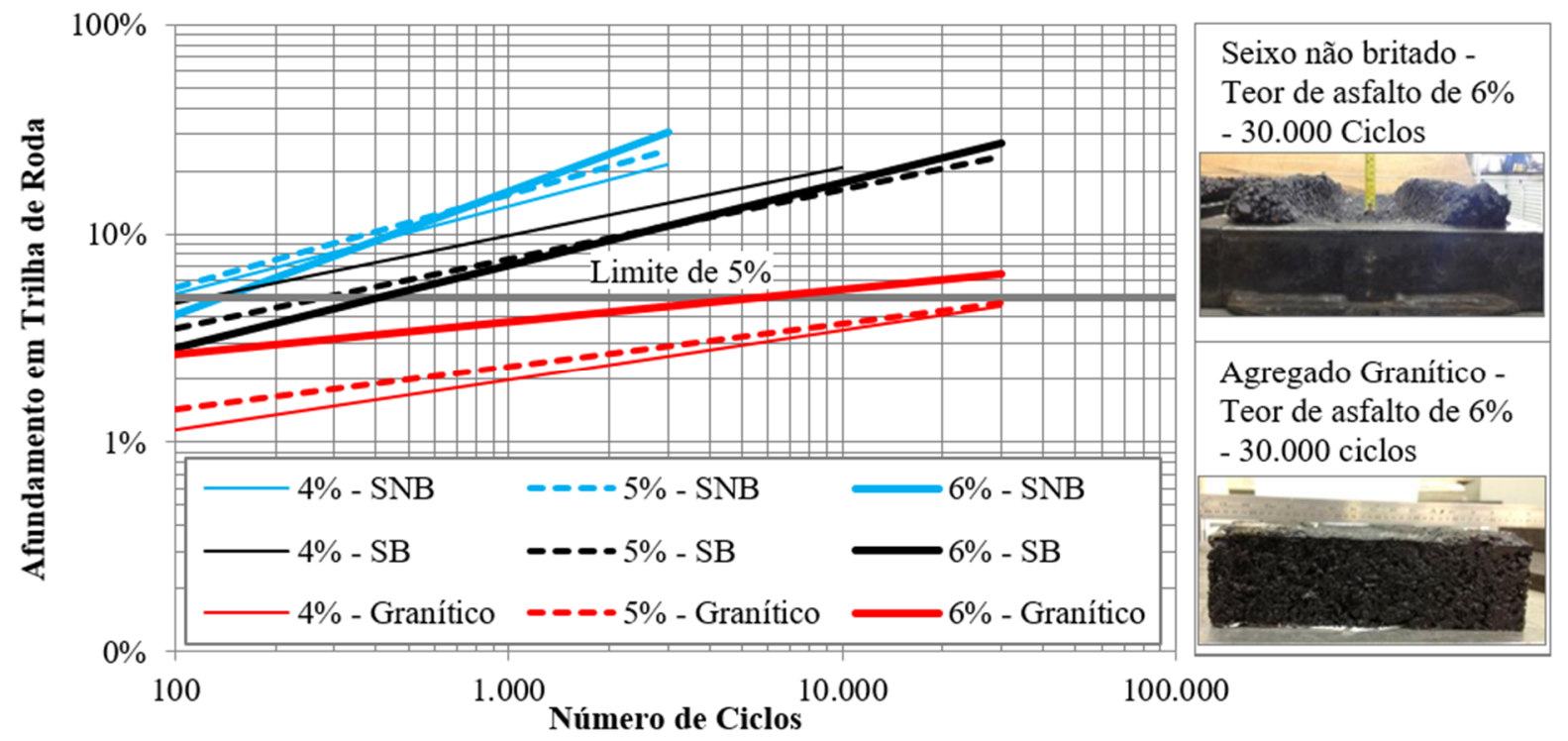

Figura 4. Percentual de Afundamento em Trilha de Roda (ATR) em função do número de ciclos para misturas com Seixo Não-Britado (SNB) e Seixo após Britagem (SB) e para as misturas com agregado granítico (granítico)

Tabela 3 - Modelos de regressão para a profundidade de afundamento a 30.000 ciclos de aplicação de carga

\begin{tabular}{lllll}
\hline \multirow{2}{*}{ Teor de Ligante } & Tipo Agregado & $\mathrm{Y}^{1}$ & $\mathrm{~A}$ & \multirow{2}{*}{$\mathrm{b}$} \\
& & $10^{-2} \mathrm{~mm}$ & $10^{-2} \mathrm{~mm}$ & \\
\hline \multirow{2}{*}{$4 \%$} & Seixo Não britado (SNB) & $2.796,05$ & 680,23 & 0,416 \\
& Seixo Britado (SB) & $1.474,39$ & 490,81 & 0,323 \\
& Granítico & 225,69 & 99,84 & 0,240 \\
\hline \multirow{2}{*}{$5 \%$} & Seixo Não britado (SNB) & $3.515,26$ & 776,98 & 0,444 \\
& Seixo Britado (SB) & $1.174,66$ & 378,21 & 0,333 \\
& Granítico & 232,51 & 115,62 & 0,205 \\
\hline \multirow{4}{*}{$6 \%$} & Seixo Não britado (SNB) & $5.948,33$ & 795,30 & 0,592 \\
& Seixo Britado (SB) & $1.356,32$ & 352,59 & 0,396 \\
& Granítico & 319,25 & 188,95 & 0,154 \\
\hline 1 Profundidade de afundamento a 30.000 ciclos. Para os casos em que os ensaios tiveram \\
\multirow{2}{*}{ que ser interrompidos antes de 30.000 ciclos, trata-se de uma extrapolação. }
\end{tabular}

Nota-se ainda, que o processo de britagem proporcionou a melhora do comportamento quanto à deformação permanente da mistura com agregado graúdo composto por seixo britado. O nível de afundamento para a condição de seixo britado é ainda proibitivo para uso corrente, pois este atingiu $10 \%$ de afundamento com apenas 1.000 a 3.000 ciclos de solicitação. Porém, constata-se que a mistura asfáltica contendo seixo britado é cerca de 3 a 5 vezes mais resistente à deformação se comparada à mistura com utilização do seixo não britado na fração graúda. $A$ mistura com seixo não britado que apresenta a menor quantidade de ligante asfáltico no teor de projeto $(4,7 \%)$ não apresenta a menor deformação permanente dentre as misturas avaliadas, comprovando a importância do arranjo de agregados. No entanto, as inclinações das retas das misturas com seixo britado para os teores de 5 e 6\% de ligante asfáltico são menores se comparadas com as inclinações das retas das misturas com seixo não britado, mostrando que a progressão do afundamento com as solicitações seria menor. 
Esse comportamento pode ser explicado pelas propriedades de forma dos agregados. No método Bailey, o fator de compactação 0,22 é recomendado para partículas com diferentes propriedades de forma para uma mistura asfáltica típica e este foi fixado para todos os cenários utilizados neste trabalho. Constata-se, na Tabela 4, que o fator 0,29 indica que a fração graúda (AG) é bem travada $(0,60)$ quando se considera a forma dos agregados com todas as faces planas. A aplicação dos fatores menores $(0,15$ a 0,24$)$ resultou no aumento dos valores de AG que representa que a fração de agregado graúdo está desbalanceada e a mistura asfáltica estará susceptível à deformação permanente. Assim, para o caso dos seixos não britado e britado, admitindo que existam condições em que as partículas apresentem todas as faces arredondadas ou uma face arredondada e duas planas, respectivamente, os fatores menores que 0,29 indicariam a falha no travamento da fração graúda. Para as misturas elaboradas com agregado granítico, o fator de compactação normalmente recomendado de 0,22 não traduziu o bom comportamento $(\%$ ATR < 5\%) quanto à deformação permanente das misturas asfálticas elaboradas com esse agregado.

Tabela 4 - Parâmetros do método Bailey em função dos fatores de compactação

\begin{tabular}{llll}
\hline \multirow{2}{*}{ Fator de Compactação } & \multicolumn{4}{l}{ Parâmetros do Método Bailey } \\
& AG & GAF & FAF \\
\hline 0,15 & 1,04 & 0,40 & 0,45 \\
0,20 & 0,98 & 0,44 & 0,44 \\
0,22 & 0,98 & 0,48 & 0,44 \\
0,24 & 0,76 & 0,43 & 0,48 \\
0,29 & 0,60 & 0,48 & 0,50 \\
Limites Recomendados & $0,50-0,65$ & $0,35-0,50$ & $0,35-0,50$ \\
\hline
\end{tabular}

A influência das propriedades de forma dos agregados também fica clara pela análise da Tabela 5 que mostra os resultados das propriedades de forma dos agregados obtidas pela utilização do AIMS. Nessa Tabela, também é apresentada a classificação dos agregados em relação a cada uma das propriedades de forma, levando em conta as médias dos resultados de cada material e utilizando a classificação proposta por Ibiapina et al. (2018). Os resultados de Forma 2D apresentados referem-se apenas à fração retida na peneira de 2,36mm. Os resultados de angularidade consideram as frações maiores que $2 \mathrm{~mm}$, uma vez que a fração fina $(<2 \mathrm{~mm})$ foi a mesma para todas as misturas.

Observa-se da Tabela 5 que, de maneira geral, o agregado granítico apresenta propriedades de forma que induzem ao melhor travamento da estrutura pétrea em comparação com o seixo antes e depois da britagem. Contudo, o agregado granítico apresenta quantidades elevadas (39\%) de partículas achatadas e alongadas na relação 3:1. Na caracterização quanto à esfericidade, as diferenças entre os tipos de agregados testados foram pequenas $(0,1)$. Desse modo, pode-se dizer que o melhor comportamento da mistura com agregado granítico quanto à resistência ao ATR, observado na Figura 4, deve-se às suas propriedades de forma, principalmente a angularidade e a textura. A quantidade limite de 30\% de partículas achatadas e alongadas na relação 3:1 recomendada pela literatura (Buchanan, 2000), não se mostrou limitante para o caso dos materiais avaliados nesse estudo. 0 aumento da angularidade e da textura fazem aumentar o ângulo de atrito interno, melhorando, sensivelmente, a resistência ao cisalhamento do esqueleto sólido e, portanto, da mistura asfáltica. 
Tabela 5 - Propriedades de forma do agregado granítico e do seixo antes e depois da britagem

\begin{tabular}{lllll}
\hline Propriedade & Tipo de Agregado & Média & Desvio Padrão & Classificação/Resultado \\
\hline \multirow{3}{*}{ Forma 2D } & Seixo não-britado & 6,3 & 2,6 & Semicircular \\
& Seixo Britado & 7,0 & 1,8 & Semicircular \\
& Granítico & 9,3 & 1,8 & Semicircular \\
\hline \multirow{3}{*}{ Angularidade } & Seixo não-britado & $1.889,5$ & 924,2 & Subarredondado \\
& Seixo Britado & $2.723,7$ & 903,8 & Subarredondado \\
& Granítico & $3.401,7$ & 817,5 & Subarredondado \\
\hline \multirow{3}{*}{ Textura } & Seixo não-britado & 157,3 & 89,7 & Polido \\
& Seixo Britado & 197,2 & 109,2 & Polido \\
& Granítico & 423,5 & 176,2 & Macio \\
\hline \multirow{4}{*}{ Esfericidade } & Seixo não-britado & 0,7 & 0,1 & Esfericidade Moderada \\
& Seixo Britado & 0,7 & 0,1 & Esfericidade Moderada \\
\hline \multirow{3}{*}{ Partículas Achatadas e Alongadas 3:1 } & Granítico & 0,6 & 0,1 & Baixa esfericidade \\
& Seixo não-britado & & & $11 \%$ \\
& Seixo Britado & & & $0 \%$ \\
& Granítico & & & $39 \%$ \\
\hline \multirow{2}{*}{ Partículas Achatadas e Alongadas 5:1 } & Seixo não-britado & & & $0 \%$ \\
& Seixo Britado & & & $0 \%$ \\
& Granítico & & & \\
\hline
\end{tabular}

Os resultados da Tabela 5 mostram que a britagem do seixo levou à alteração das propriedades de forma, principalmente quanto à angularidade e à forma 2D. Entretanto, a britagem não foi suficiente para que esses índices apresentassem valores equivalentes ou melhores do que aqueles encontrados para o agregado granítico. Outro fator relevante de melhora é a angularidade apresentada pelos seixos britados, frente aos naturais. Assim, justificam-se os resultados intermediários de ATR das misturas asfálticas com seixo britado em relação às misturas com seixo não britado e às misturas com agregado granítico apresentados na Figura 4.

\section{CONCLUSÕES}

Considerando os questionamentos que delimitaram o objetivo do trabalho, a principal conclusão é que os parâmetros de forma e textura dos agregados graúdos são fatores relevantes para a resistência à deformação permanente de misturas asfálticas densas. A mistura asfáltica contendo seixo britado foi cerca de 3 a 5 vezes mais resistente à deformação se comparada à mistura com utilização do seixo não britado para uma mesma distribuição granulométrica e mesmo teor de ligante asfáltico. Além disso, o fator de compactação para a elaboração da composição granulométrica sugerido pelo método Bailey é dependente do tipo do agregado utilizado, incluindo suas propriedades de forma. Assim, é prudente a investigação de fatores de compactação ajustados em função das características morfológicas dos agregados de maneira a garantir a melhoria da resistência ao ATR dos concretos asfálticos.

A preocupação em relação ao efeito da quantidade de partículas achatadas e alongadas na relação de 3:1 não se mostrou válida quanto à resistência à deformação permanente. A quantidade desse tipo de agregado (até o limite de 39\% para este trabalho) não exerceu influência relevante quanto aos afundamentos.

\section{AGRADECIMENTOS}

Os autores agradecem à Coordenação de Aperfeiçoamento de Pessoal de Nível Superior (CAPES) pela bolsa de pesquisa ao primeiro autor e ao Conselho Nacional de Desenvolvimento Científico e Tecnológico (CNPq) pela bolsa aos demais autores. Ao grupo de Caracterização Avançada de Materiais para Pavimentação (CAMP) da UFC pela realização do Processamento Digital de Imagens e ao Laboratório de Tratamento de Minérios da Escola Politécnica da USP pela disponibilização dos britadores. 


\section{REFERÊNCIAS}

AASHTO (2014) T 283. Standard Method of Test for Resistance of Compacted Asphalt Mixtures to Moisture Induced Damage. American Association of State Highway and Transportation Officials.

Advanced Asphalt Technologies (2011) A Manual for Design of Hot Mix Asphalt with Commentary. Nacional Cooperative Highway Research Program - NCHRP. Washington: Report 673.

Asphalt Institute (2001) SUPERPAVE Mix Design Series SP-2. Asphalt Institute Research Center, Lexington.

ASTM (2011) D2041/D2041M - 11. Standard Test Method for Theoretical Maximum Specific Gravity and Density of Bituminous Paving Mixtures. American Society for Testing and Materials.

ASTM (2013) D2726/D2726M - 13. Standard Test Method for Bulk Specific Gravity and Density of Non-Absorptive Compacted Bituminous Mixtures. American Society for Testing and Materials.

ASTM (2015) D1188 - 07. Standard Test Methods for Bulk Specific Gravity and Density of Compacted Bituminous Mixtures Using Coated Samples. American Society for Testing and Materials

Bastos, J. B. S. (2016) Consideração sobre a Deformação Permanente de Pavimentos Asfálticos no Dimensionamento MecanísticoEmpírico. Tese de doutorado - Universidade Federal do Ceará, Centro de Tecnologia, Programa de Pós-Graduação em Engenharia de Transportes. Fortaleza, p. 200. Disponível em: <http://www.repositorio.ufc.br/bitstream/riufc/23173/1/2016_tese_jbsbastos.pdf>.

Botasso, G.; Garcia, L.; Nieto, J. P.; Soengas, C. (2012) Bailey Method Design for a Dense Asphalt Concrete and its Influence on Permanent Plastic Deformations Resistance. Revista Científico Tecnológica Departamento Ingeniería de Obras Civiles, p. 21 29.

Bernucci, L. L. B.; Motta, L. M. G.; Ceratti, J. A. P.; Soares, J. B (2010) Pavimentação Asfáltica: Formação Básica para Engenheiros. 3a. ed. Rio de Janeiro: PETROBRAS: ABEDA.

Buchanan, M. S. (2000) Evaluation of the Effect of Flat and Elongated Particles on the Performance of Hot Mix Asphalt Mixtures. National Center for Asphalt Technology - NCAT. Auburn. (NCAT 00-03).

Carvalho, C. A. B. (1997) Estudo da Contribuição das Deformações Permanentes das Camadas de Solo na Formação das Trilhas de Roda num Pavimento Flexível. Tese de Doutorado - EESC/ USP. São Carlos, p. 298.

Choi, Y. T.; Kim, Y. R. (2014) Implementation and Verification of a Mechanistic Permanent Deformation Model (shift model) to Predict Rut Depths of Asphalt Pavement. Road Materials and Pavement Design, v. 15, p.195 - 218. DOI: 10.1080/14680629.2014.927085.

Cunha, M. B. (2004) Avaliação do Método Bailey de Seleção Granulométrica de Agregados para Misturas Asfálticas. Dissertação de Mestrado - EESC/ USP. São Carlos, p. 105. Disponível em: <https://teses.usp.br/teses/disponiveis/18/18137/tde19032007-180257/pt-br.php>.

Dubois, V.; C. De La Roche, e O. Burban (2010) Influence of the Compaction Process on the Air Void Homogeneity. Construction and Building Materials, p. 885 - 897. DOI: 10.1016/j.conbuildmat.2009.12.004.

DNER (1995) ME 043/95. Misturas Betuminosas a Quente - Ensaio Marshall. Departamento Nacional de Estradas de Rodagem.

Eslaminia, M.; Thirunavukkarasu, S.; Guddati, M. N. e Kim, Y. R (2012) Accelerated pavement performance modeling using layered viscoelastic analysis. Proceedings of the 7th International RILEM Conference on Cracking in Pavements, p. 497-506. DOI: 10.1007/978-94-007-4566-7_48

European Committee for Standardization (2003) EN 12697-33:2003+A1:2007. Bituminous Mixtures - Test Methods for Hot Mix Asphalt - Part 33: Specimen Prepared by Roller Compactor.

European Committee for Standardization (2003) EN 12697-22:2003+A1:2007. Bituminous Mixtures - Test Methods for Hot Mix Asphalt - Part 22: Wheel Tracking.

Foster, C. R. (1982) Development of Marshall Procedures for Designing Asphalt Paving Mixtures. National Asphatl pavement Association (NAPA), p. 1 - 22.

Harvey, J. T.; S. L. Wissman e C. L. Monismith (2009) Rutting Characterization of Asphalt Concrete Using Simple Shear Test. In: Y. R. Kim. Modeling of Asphalt Concrete. McGrawHill Books, Cap. 10.

Huang, B.; X. Chen; X. Shu; E. Masad; E. Mahmoud (2009) Effects of Coarse Aggregate Angularity and Asphalt Binder on Laboratory-Measured Permanent Deformation Properties of HMA. International Journal of Pavement Engineering, v. 10, n. 1, p. 19 - 28. DOI: $10.1080 / 10298430802068915$

Huber, G. A.; J. C. Jones; P. E. Messermith (1998) Contribution of Fine Aggregate Angularity and Particle Shape to Superpave Mixture Performance. Transportation Research Record: Journal of the Transportation Research Board, Washington, n. 1609, p. 28 - 35. DOI: 10.3141/1609-04.

Hunter, A. E.; L. McGreavy; G. D. Airey (2009) Effect of Compaction Mode on the Mechanical Performance and Variability os Asphalt Mixtures. Journal of Transportation Engineering, v. 135, n. 11, p. 839 - 851.

Ibiapina, D. S.; Castelo Branco, V. T. F.; Diógenes, L. M.; Motta, L. M. G.; Freitas, S. M. (2018) Proposição de um sistema de Classificação das Propriedades de Forma de Agregados Caracterizados com o uso do Processamento Digital de Imagens a partir de Materiais Oriundos do Brasil. Transportes, v. 26, n. 4, p. 116-128. DOI: https://doi.org/10.14295/transportes.v26i4.1510.

Khan, Z. A.; H. I. A. Wahab; I. Asi; R. Ramadhan (1998) Comparative Study of Asphalt Concrete Laboratory Compaction Methods to Simulate Field Compaction. Construction and Building Materials, p. 373 - 384. DOI: 10.1016/S09500618(98)00015-4.

Kim, D.; Kim, Y. R. (2017) Development of Stress Sweep Rutting (SSR) Test for Permanente Deformation Characterization of Asphalt Mixture. Construction and Building Materials, v. 154, p. 373 - 383. DOI: 10.1016/j.conbuildmat.2017.07.172. 
Laboratoire Central des Ponts et Chaussées - LCPC (2007) Manuel LPC d'aide à la formulation. Paris.

Laboratoire Central des Ponts et Chaussées - LCPC (1994) Conception et dimensionnement des structures de chaussée: Guide Technique. Paris: Service D'Études Techniques des Routes et Autoroutes - SETRA.

Leandro, R. P.; K. L. Vasconcelos; L. L. B. Bernucci (2017) Evaluation of the Laboratory Compaction Method on the Air Voids and the Mechanical Behavior of Hot Mix Asphalt. Construction and Building Materials, v. 156, p. 424 - 434 . DOI: 10.1016/j.conbuildmat.2017.08.178.

Manjunath, K. R; Poornachandra Dev, N. B. (2014) Design of Hot Mix Asphalt Using Bailey Method of Gradation. International Journal of Research in Engineering and Technology, v. 3, p. 386 - 393.

Mohamed, S. O.; Abdelbaset A. A. (2016) Controlling Rutting Performance of Hot Mix Asphalt. International Journal of Scientific \& Engineering Research, v. 6, p. $872-882$.

Motevalizadeh, S. M.; Ayar, P.; Motevalizadeh, S. H.; Yeganehd, S.; Amerid, M.; Bemanad, K (2018) Investigating the Impact of Different Loading Patterns on the Permanent Deformation Behaviour in Hot Mix Asphalt. Construction and Building Materials, v. 167, p. 707 - 715. DOI: 10.1016/j.conbuildmat.2018.02.049.

Moura, E. (2010) Estudo de Deformação Permanente em Trilha de Roda de Misturas Asfálticas em Pista e em Laboratório. Tese de Doutorado - EP/ USP. São Paulo, p. 299. Disponível em: https://www.teses.usp.br/teses/disponiveis/3/3138/tde17082010-094223/pt-br.php.

Pan, T.; E. Tutumluer; S. H. Carpenter (2006) Effect of Coarse Aggregate Morphology on Permanent Deformation Behavior of Hot Mix Asphalt. Journal of Transportation Engineering, v. 132, n. 7, p. 580 - 589. DOI: 10.1061/(ASCE)0733947X(2006)132:7(580).

Roberts, F. L. (1996) Hot Mix Asphalt Materials, Mixture Design, and Construction. 2a. ed. Lanham: National Asphalt Pavement Association Research and Education Foundation - NAPA.

Sousa, J. B. ; J. Harvey ; L. Painter ; J. A. Deacon ; C. L. Monismith (1991) Evaluation of Laboratory Procedures for Compacting Asphalt-Aggregate Mixtures. Strategic Highway Research Program (SHRP). Washington, D.C.

Stakston, A. D; H. U. Bahia; J. J. Bushek (2002) Effect of Fine Aggregate Angularity on Compaction and Shearing Resistance of Asphalt Mixtures. Transportation Research Record: Journal of the Transportation Research Board, Washington, n. 1789, p. 14 - 24. DOI: 10.3141/1789-02.

Vasconcelos, K; L; F. Evangelista Júnior; J. B. Soares. Análise da Estrutura Interna de Misturas Asfálticas. In: XVII Congresso Brasileiro de Pesquisa e Ensino em Transportes, 2005, Recife. Anais XVII Congresso Brasileiro de Pesquisa e Ensino em Transportes, 2005.

Vavrik, W. R.; R. J. Fries; S. H. Carpenter (1999) Effect of Flat and Elongated Coarse Aggregate on Characteristics of Gyratory Compacted Samples. Transportation Research Record: Journal of Transportation Research Board, Washington, n. 1681, p. 28 - 36. DOI: 10.3141/1681-04.

Vavrik, W. R.; W. J. Pine; S. H. Carpenter (2002a) Aggregate Blending for Asphalt Mix Design: Bailey Method. Transportation Research Record: Journal of the Transportation Research Board, Washington, n. 1789, p. 146 - 153. D0I: 10.3141/1789-16.

Vavrik, W. R.; G. Huber; W. J. Pine; S. H. Carpenter; R. Bailey (2002 ${ }^{\mathrm{b}}$ ) Bailey Method for Gradation Selection in HMA Mixture Design. Transportation Research Board. Circular Number E-C044.

Wang, Y.; A. H. Norouzi; Y. R. Kim (2016) Comparison of Fatigue Cracking Performance of Asphalt Pavements Predicted by Pavement ME and LVECD Programs. Transportation Research Record: Journal of the Transportation Research Board, Washington, n. 2590, p. 44 - 55. DOI: 10.3141\%2F2590-06

Watson, D. E.; E. R. Brown; J. Moore (2005) Comparison of Superpave and Marshall Mix Performance in Alabama. Transportation Research Record: Journal of the Transportation Research Board, Washington, n. 1929, p. 133 - 140. D0I: 10.3141/192916.

West, R. C.; J. R. Moore (2006) Evaluating Georgia's compaction requirements for Stone Matrix Asphalt Mixtures. The Georgia Department of Transportation. Final Report. DOI: https://doi.org/10.3141/2001-11.

Witczak, M. W.; K. Kaloush; T. Pellinen; M. El-Basyouny, H. Von Quintus (2002) Simple performance test for superpave mix design. National Cooperative Highway Research Program, NCHRP Report 465.

Yoder, E. J. e M. W. Witkzac (1975) Principles of Pavement Design. 2a. ed. New York: John Wiley \& Sons. 